\title{
Caminhos da Justiça Restaurativa para os conflitos infanto-juvenis no Brasil*
}

\section{The ways of Restorative Justice for children and youth conflicts in Brazil Los caminos de la Justicia Restaurativa para los conflictos infantiles y juveniles en Brasil}

\author{
Maria de Lourdes Alves Lima Zanatta ${ }^{1}$ \\ (D) http://orcid.org/0000-0002-8509-7168 \\ Ana Claudia Delfini Capistrano de Oliveira ${ }^{2}$ \\ (iD) http://orcid.org/0000-0002-7154-9020 \\ Univali - Universidade do Vale do Itajaí, Santa Catarina, Brasil
}

DOI: http://dx.doi.org/10.21803\%2Fpenamer.11.20.501

\begin{abstract}
Resumo
O objetivo desse artigo, do tipo analítico, é analisar três programas em três diferentes localidades, cada um com uma abordagem peculiar na aplicação da Justiça Restaurativa brasileira. A aplicação da Justiça Restaurativa iniciou-se em território brasileiro a partir do ano de 2005, por meio de parceria entre o PNUD e o Ministério da Justiça, atendendo a recomendações da ONU para a utilização de práticas de Justiça Restaurativa. Tal aplicação se deu por meio de projetos piloto, com vistas a uma reestruturação do Poder Judiciário Brasileiro, adaptada à realidade contemporânea no que toca ao tratamento de conflitos criminais, seguindo as tendências de justiça a nível internacional. A metodologia para esse artigo foi efetuada mediante revisão bibliográfica e os resultados principais apontam que a mediação vítima-ofensor e os círculos restaurativos são as técnicas de Justiça Restaurativa mais utilizadas pelos programas brasileiros.
\end{abstract}

Palavras chave: Justiça Restaurativa, Infancia, Juventude.

Abstract

This article aims to analyze three programs in three different Brazilian locations, each one with a unique approach to the application of Brazilian Restorative Justice. The application of Restorative Justice began in Brazil from 2005, through a partnership between UNDP and the Ministry of Justice, in line with UN recommendations for the use of Restorative Justice practices. Pilot projects were used with the aim of restructuring the Brazilian Judiciary, adapted to the contemporary reality regarding the treatment of criminal conflicts, following the trends of justice at the international level. The methodology used was a bibliographic review and the main results point out that victim-offender mediation and restorative circles are the Restorative Justice techniques most used by Brazilian programs.

Keywords: Restorative Justice, Childhood, Youth.

\section{Resumen}

El objetivo de este artículo, del tipo analítico, es analizar los tres programas en tres diferentes localidades, cada uno con un abordaje especifico en la aplicación de la Justicia Restaurativa brasileña. La aplicación de la Justicia Restaurativa tuvo su inicio en el territorio brasileño a partir del año de 2005, por medio de una cooperación entre el PNUD y el Ministerio de la Justicia, atendiendo a las recomendaciones de las Naciones Unidas para la utilización de prácticas de Justicia Restaurativa. Tal aplicación se dio por medio de proyectos piloto, objetivando una reestructuración del Poder Judicial Brasileño, adaptada a la realidad contemporánea al tratamiento de conflictos criminales, siguiendo las tendencias de justicia a nivel internacional. La revisión bibliográfica fue la metodología utilizada y los resultados indican que la mediación víctima-ofensor y los círculos restaurativos son las técnicas de Justicia Restaurativa más utilizadas por los programas brasileños.

Palabras clave: Justicia Restaurativa, Infancia, Juventud.

Cómo referenciar este artículo: Alves, M. \& Delfini Capistrano, A. (2018). Caminhos da Justiça Restaurativa para os conflitos infanto-juvenis no Brasil. Pensamiento Americano, 11(20), 141-155. http://dx.doi.org/10.21803\%2Fpenamer.11.20.501

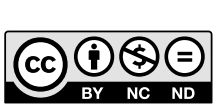

\section{Recibido: Enero 10 de 2018 • Aceptado: Marzo 2 de 2018}

Artigo derivado do Grupo de Pesquisa do Cnpq "Sociologia da infância, relações de gênero e políticas públicas".

1. Mestre pela Universidade do Minho em Portugal. malu@univali.br

2. Mestre e doutora em Sociologia pela Universidade Federal de Santa Catarina. anaclaudia.univali@gmail.com 


\section{Introdução}

A instituição da Justiça Restaurativa no Brasil decorre da busca por métodos de garantir maior celeridade e eficiência à Justiça Brasileira, que vinha sofrendo as mazelas da morosidade e dos altos custos processuais há longos anos. Aos poucos, as discussões teóricas começaram a surtir efeito no campo da realidade fática, sobretudo no que toca à efetivação do direito de acesso à justiça. A aplicação da justiça restaurativa a crianças e adolescentes segue uma tendência mundial, destacando-se, em especial o caso da Nova Zelândia. Da mesma forma, os países que fazem uso da Justiça Restaurativa no Direito Penal destinam sua aplicação aos casos menos graves, como ocorre no Brasil. Percebe-se que a mediação vítima-ofensor e os círculos restaurativos são as técnicas de justiça restaurativa mais utilizadas pelos programas brasileiros.

Neste contexto, merece destaque a figura dos facilitadores, pessoas treinadas para a condução dos procedimentos restaurativos e das equipes de profissionais de várias áreas, envolvendo, principalmente, psicólogos e assistentes sociais, que atendem as partes e contribuem para o entendimento entre estas. A procura por reformas operacionais na justiça brasileira deu-se, em um primeiro momento, ainda na década de 1990, com o advento da Lei ${ }^{\circ}$ 9.099/95, que instituiu os Juizados Especiais Cíveis e Criminais que instituiu tratamento diferenciado aos crimes de menor potencial ofensivo, os quais eram processados de acordo com a sistemática específica dos juizados especiais. Contravenções penais e crimes cuja pena abstrata não ultrapasse dois anos passaram a fazer parte da ritualística dos Juizados Especiais Criminais. Observa-se que os princípios orientadores dos Juizados Criminais assemelham-se a alguns fundamentos da justiça restaurativa. Contudo, o modus operandi dos juizados especiais assemelha-se a uma versão mais branda da Justiça Retributiva, e não em uma forma alternativa de justiça, que lance um olhar inovador e harmonioso ao conflito criminal. De fato, a aplicação da Justiça Restaurativa iniciou-se em território brasileiro a partir do ano de 2005, por meio de parceria entre o PNUD e o Ministério da Justiça, atendendo a recomendações da ONU para a utilização de práticas de Justiça Restaurativa. Tal aplicação se deu por meio de projetos piloto, com vistas a uma reestruturação do Poder Judiciário Brasileiro, adaptada à realidade contemporânea no que toca ao tratamento de conflitos criminais, seguindo as tendências de justiça a nível internacional.

Tendo em vista os diversos projetos de justiça restaurativa criados no Brasil, que dão ensejo à mudança no tratamento dos conflitos criminais no país, este artigo analisa três programas em três diferentes localidades, cada um com uma abordagem peculiar na aplicação da justiça restaurativa brasileira.

Na cidade de Porto Alegre, desenvolveu-se o projeto "Justiça para o século XXI", implementado na $3^{\text {a }}$ Vara da Infância e Juventude da comarca, tendo foco nas crianças e adolescen- 
tes autoras de ato infracional. Em São Caetano do Sul, estabeleceu-se o projeto intitulado "Justiça e Educação: parceria para a cidadania", que propunha a parceria entre o Poder Judiciário e a Secretaria da Educação, buscando aplicar as práticas de Justiça Restaurativa nos conflitos ocorridos no ambiente escolar. O projeto de São Caetano do Sul também é direcionado às crianças e adolescentes, e destaca-se justamente pela atuação conjunta do Poder Judiciário e das Escolas, como o título do projeto evidencia. Além da utilização das práticas de Justiça Restaurativa nos processos de apuração de ato infracional, o projeto em questão também instituiu técnicas de mediação e conciliação nos conflitos ocorridos no ambiente escolar. A parceria entre a Secretaria do Estado de São Paulo e a Secretaria de Justiça, contava, na prática, com o envolvimento entre as escolas locais, o Poder Judiciário, o Ministério Público e o Conselho Tutelar, visando a efetivação dos direitos fundamentais das crianças e adolescentes. Inicialmente, o projeto "Justiça e Educação: parceria para a cidadania" foi implementado em três escolas da cidade de São Caetano do Sul, e, devido aos resultados positivos obtidos, expandiu-se para outras onze escolas locais.

Os projetos-piloto iniciados em 2005 abriram caminho para o surgimento de outros projetos de Justiça Restaurativa, em diversas comarcas brasileiras. A título de exemplo, pode-se citar o "Projeto Mediar", idealizado pela Polícia Civil de Belo Horizonte, voltado para a mediação policial nos casos de pequenas infrações penais envolvendo questões de relacio- namento, além do Projeto Justiça Restaurativa idealizado pelo Poder Judiciário do Estado de Minas Gerais, também em Belo Horizonte; o projeto desenvolvido na comarca de São José de Ribamar, pelo Tribunal de Justiça do Estado do Maranhão, aplicado tanto a nível judicial como nas escolas; o projeto de mediação infanto-juvenil implementado pelo Tribunal de Justiça do Estado de Santa Catarina na comarca de Joinville.

Por fim, em Brasília, o "Projeto Justiça Comunitária do Distrito Federal” destina-se aos adultos praticantes de crimes de menor potencial ofensivo. Os projetos piloto supramencionados destacam-se pela aproximação do Poder Judiciário de outros entes sociais, visando garantir a participação da comunidade nos processos de Justiça Restaurativa.

\section{O Projeto "Justiça e Educação: uma} Parceria para a Cidadania”, na Cidade de São Caetano do Sul

O projeto-piloto conduzido na cidade de São Caetano do Sul destaca-se pela atuação conjunta do Poder Judiciário e das escolas da rede pública, no afã de utilizar os princípios da Justiça Restaurativa nos conflitos existentes no ambiente escolar. O projeto em questão foi criado visando o desenvolvimento de métodos democráticos para a solução de conflitos, notadamente com o envolvimento comunitário na tomada de decisões. Desta forma, buscou-se aliar os esforços despendidos pelo Poder Judiciário, pelas escolas e pela comunidade, a fim de promover a responsabilização dos in- 
divíduos pelos atos nocivos causados e aplicar medidas mais condizentes com a reparação dos danos, promovendo-se, assim, a cidadania. Inicialmente, o projeto-piloto da cidade de São Caetano do Sul voltou-se em especial para a solução de conflitos envolvendo crianças e adolescentes no ambiente escolar. Neste sentido, o projeto fundou-se em três objetivos principais, que consistiam na resolução dos conflitos no próprio ambiente escolar, evitando o acionamento do Poder Judiciário; a utilização de círculos restaurativos na apuração de atos infracionais ocorridos fora do ambiente escolar e comunitário; e o fortalecimento das redes comunitárias, possibilitando uma atuação mais efetiva dos agentes estatais e não-estatais no amparo dos direitos da criança e do adolescente. A efetivação de uma parceria entre escolas e Poder Judiciário é de grande valia em razão do papel que a instituição escolar ocupa tanto no plano individual como coletivo.

Tratando-se de uma das primeiras e mais intensas experiências sociais do indivíduo, a ocorrência de conflitos no ambiente escolar é natural. Entretanto, por diversas vezes estes conflitos ultrapassam os limites do desentendimento interpessoal e adentram a seara da ilegalidade, englobando, por muitas vezes, agressividade e violência. Ao reproduzir diversos aspectos que se aplicam à sociedade como um todo, as escolas têm o condão de potencializar os efeitos da sanção aplicada aos infratores e da exclusão social daqueles comumente tidos como desajustados. Percebe-se que a escola recebe, concomitantemente, a responsabilidade pela transformação da realidade social e pela correção dos indivíduos que não se adéquam às regras nela impostas. Cria-se, assim, um paradoxo, agravando-se ainda mais a situação pelo fato de, via de regra, as instituições escolares carecerem de meios eficazes para solucionar os problemas nela existentes. De acordo com Melo (2006, p.05):

De fato, à escola tende todo o processo socioeducativo. É para lá que se busca o retorno do adolescente em conflito com a lei. Ainda que o ato infracional não tenha sido cometido no entorno daquela escola, sendo o adolescente oriundo de tal escola, será no contexto dela que haverá de seguir sua vida e é nela que haverá de encontrar o espaço de acolhimento e de reflexão sobre as razões e conseqüências de seu ato, reavaliando sua conduta e seu modo de ação no mundo. Tomar, então, a escola ao mesmo tempo como o ponto de partida e de chegada deste processo de inclusão e de emancipação, simboliza ao adolescente de modo mais concreto o sentido da atuação da justiça na resolução de conflitos.

Desta forma, o projeto Justiça e Educação, ao criar a aliança entre o Poder Judiciário, as escolas e a comunidade, visa fornecer o aparato necessário para lidar com os conflitos no ambiente escolar envolvendo adolescentes em conflito com a lei. Ademais, a utilização de técnicas pautadas no critério da reparação do dano se mostra mais condizente com a prote- 
ção dos direitos das crianças e adolescentes, público alvo da situação em tablado. Ao iniciar, em 2005, o projeto sul-caetanense englobava três escolas da rede pública estadual sediadas na cidade, as quais, juntamente do Poder Judiciário e do Conselho Tutelar da comarca, tornaram-se palco da aplicação de técnicas de Justiça Restaurativa. Na primeira fase do projeto-piloto, a técnica utilizada consistia nos círculos restaurativos, encontros nos quais as partes envolvidas no conflito se fazem presentes e são guiadas por um facilitador. O objetivo dos círculos restaurativos é o de aproximar as partes, fazendo com que ambas se exponham, visando a obtenção de um consenso quanto ao que deve ser feito em relação à ofensa causada. Esta dinâmica, baseada em métodos de justiça restaurativa utilizados por comunidades aborígenes ao redor do mundo e adaptada à realidade local, realizava-se de acordo com o procedimento descrito por Melo, Ednir y Yazbek (2008, p.13):

A dinâmica do círculo se desenvolve por meio de três etapas: compreensão mútua - as partes passam a se perceber como semelhantes; luto e transformação - as escolhas e responsabilidades envolvidas no ato da transgressão são reconhecidas; acordo - participantes desenvolvem ações que reparem, restaurem e reintegrem.

Os círculos restaurativos eram realizados nas escolas em que haviam ocorrido os conflitos, envolvendo alunos, professores e colabo- radores da escola nestes procedimentos. Nos casos em que os conflitos não haviam ocorrido no ambiente escolar, então os círculos restaurativos eram realizados no fórum da comarca, com a participação do Juiz da Vara da Infância e Juventude e de um representante do Ministério Público, aliados a assistentes sociais. $\mathrm{O}$ Conselho Tutelar também surgia como área de resolução amistosa de conflitos, voltado para casos de crianças e adolescentes em situação de vulnerabilidade. O magistrado Eduardo Melo, coordenador do projeto em foco, evidencia dois aspectos merecedores de destaque em relação aos círculos restaurativos. A primeira diz respeito ao próprio procedimento desenvolvido nas escolas, na qual os facilitadores eram membros da instituição, junto das assistentes sociais. O que chama a atenção é a presença de co-facilitadores, preferencialmente alunos da própria escola, e, assim, colegas das partes envolvidas no conflito. Esta participação não apenas tinha aspectos positivos no que diz respeito à aproximação entre vítima e ofensor, mas também, sob o aspecto simbólico, de que os jovens exercem um papel fundamental na construção da justiça. $\mathrm{O}$ outro aspecto encontra-se voltado à relação entre o adolescente infrator $\mathrm{e}$ sua comunidade, na qual, via de regra, as conseqüências do ato infracional são sentidas de modo mais intenso (Melo et al., 2008).

Tendo em vista que a comunidade poderia não compreender o procedimento dos círculos restaurativos e a lógica de reparação que circunda a Justiça Restaurativa, aconselhava-se ao jovem infrator a realizar atividades no seio 
comunitário, a fim de recuperar a confiança daqueles que o cercam. A preocupação em relação à eficiência dos círculos restaurativos não se exauria apenas na aplicação da técnica em si, mas também na recuperação e reinserção social do indivíduo. Pode-se afirmar que, por meio da participação conjunta dos entes envolvidos, incluindo as escolas e agentes comunitários, aproximava-se mais da proteção integral do adolescente e da reparação do dano por ele causado. A utilização dos círculos restaurativos contribui para a superação do ideal de punição e disciplina que impera no âmbito jurídico, mas também apresenta reflexos em outros institutos caracterizados como mecanismos de controle social, sobretudo no ambiente escolar.

Durante o primeiro ano, o projeto sul-caetanense manteve os moldes iniciais, adotando apenas os círculos restaurativos como procedimento de base. Entretanto, os resultados positivos obtidos pelo projeto em seu ano inicial levaram à expansão do projeto, e, conseqüentemente, à busca por novas técnicas que ampliassem o leque opcional no tratamento dos conflitos. Desta maneira, no ano de 2006, todas as 12 escolas do município de São Caetano do Sul passaram a participar do projeto piloto, aumentando o número de pessoas em treinamento de capacitação para atuar como facilitadores. Ao mesmo tempo, formaram-se novas lideranças educacionais para atuar junto daquelas formadas em 2005, auxiliando na condução do projeto. Observou-se que para que a ampliação do projeto Justiça e Educação fosse bem sucedida, seria necessário ampliar também as frontei- ras de aplicação das técnicas restaurativas. Isto, pois, o aumento da demanda de casos em busca dos círculos restaurativos sobrepunha a capacidade das escolas para lidarem com os mesmos, sobretudo aqueles conflitos cuja origem se dava além dos muros escolares. Na mesma senda, a utilização exclusiva dos círculos restaurativos limitava o potencial de solução pacífica de conflitos envolvendo adolescentes, visto que, em casos peculiares, fazia-se necessária a adaptação dos moldes aplicados pelos facilitadores. Logo, ansiava-se pelo advento de novas técnicas de justiça restaurativa, a fim dar continuidade ao crescimento do projeto.

Com o intuito de lapidar o projeto, após uma avaliação do mesmo, verificou-se a necessidade de uma melhor capacitação dos envolvidos nos círculos restaurativos, bem como na interação entre as técnicas utilizadas e os entes envolvidos. Percebeu-se que era fundamental aperfeiçoar as técnicas dos facilitadores que tinham o primeiro contato com as partes, pois este ponto era crucial para o sucesso do procedimento restaurativo. Percebe-se que, através da experiência, novas direções foram apontadas no projeto-piloto sul-caetanense, adequando as técnicas utilizadas às necessidades reais e locais.

Destaca-se a percepção de que há diversos atores essenciais para que o procedimento restaurativo tenha efeitos, não se restringindo ao facilitador que conduz a mediação e o diálogo entre as partes, mas também os envolvidos na apuração da infração e no acompanhamento 
das partes. A devida preparação de todos os envolvidos, portanto, tornou-se indispensável. O projeto-piloto passou por uma reformulação ao final do ano de 2007, sendo traçados novos objetivos e delineando novamente seu público alvo, a fim de abranger os círculos restaurativos comunitários. A integração entre diversos entes estatais, presente até o momento, foi mantida. De modo geral, pode-se afirmar que o projeto, inicialmente voltado à aplicação da Justiça Restaurativa nas escolas locais, expandiu-se para o tratamento de conflitos envolvendo crianças e adolescentes, bem como conflitos familiares e comunitários. Segundo dados oficiais, entre os anos de 2005 e 2007, foram realizados 260 círculos restaurativos, resultando em 231 acordos. Destes, 223 foram devidamente cumpridos, equivalente a uma média de $88,84 \%$ de resultados positivos em círculos restaurativos, e de $96,54 \%$ de cumprimento nos acordos firmados pelo projeto de Justiça Restaurativa. A maioria dos círculos restaurativos (160) foram realizados nas escolas, seguido pelos círculos comunitários (61) e pelos realizados nos fóruns (39). Os conflitos mais comuns envolviam a prática de ameaça, violência física, bullying, ofensa, desentendimento, furto e roubo (Melo et al., 2008).

Em âmbito estadual, os resultados obtidos em São Caetano do Sul levaram à instituição de projetos semelhantes em cidades próximas, ampliando a parceria entre o Poder Judiciário e as escolas da rede pública. Tal parceria é fundamental para a reformulação do modo de lidar com os conflitos no ambiente escolar.
Além do pioneirismo na aplicação da Justiça Restaurativa, há outros aspectos a serem destacados no que tange ao projeto sul-caetanense. O primeiro deles diz respeito à já mencionada atuação conjunta entre diversos entes do Poder Público no intuito de promover a justiça de modo harmonioso e efetivar os direitos fundamentais das crianças e adolescentes. A promoção de círculos restaurativos nas escolas, promovendo uma nova forma de resolução dos conflitos ocorridos neste ambiente também é merecedora de destaque. Historicamente, os mecanismos utilizados nas escolas refletem o método retributivo de solução de conflitos, com a primazia da aplicação de sanções e direcionamento dos casos tidos como mais graves ao Poder Judiciário. O estímulo da resolução dos conflitos em âmbito escolar por meio da Justiça Restaurativa condiz com a doutrina da proteção integral das crianças e adolescentes. Mais do que isso, instaura-se uma pedagogia que incentiva o diálogo e a alteridade como medidas essenciais ao convívio interpessoal, em detrimento da punição como única forma de lidar-se com os conflitos.

Entende-se que a exposição a procedimentos de Justiça Restaurativa desde a tenra idade, e no ambiente escolar, local de tamanha importância para a formação individual, é uma medida fundamental para a perpetuação da Justiça Restaurativa no futuro. A conscientização dos jovens envolvidos nos círculos restaurativos e os resultados positivos nestes obtidos demonstram que estas práticas tem o condão de suprimir as lacunas existentes na crise da Justiça Retributiva. 
2. O Projeto "Justiça para o século XXI", na Cidade de Porto Alegre

$\mathrm{Na}$ esteira do projeto desenvolvido na comarca de São Caetano do Sul, outros dois projetos foram pioneiros na aplicação da Justiça Restaurativa em território brasileiro. Um deles, ao qual dar-se-á maior atenção no momento, consiste no projeto Justiça para o século XXI, implementado no ano de 2005 na $3^{\text {a }}$ Vara da Infância e Juventude da comarca de Porto Alegre. O Poder Judiciário do Rio Grande do Sul destaca-se, a nível nacional, por uma jurisprudência menos conservadora e mais atenta às transformações sociais. Este posicionamento do órgão judicante no estado-membro possibilitou o desenvolvimento de projetos visando a adequação da aplicação da norma à realidade fática, tendo em vista que, muitas vezes, o preceito normativo se desencontra com o ideal de justiça. Percebe-se que estudos sobre a Justiça Restaurativa já vinham sendo desenvolvidos desde os anos 2000, com aplicações no modo de processamento das medidas socioeducativas na $3^{\text {a }}$ Vara da Infância e Juventude de Porto Alegre. Na referida Vara, sob a atuação do magistrado Leonardo Brancher, utilizava-se uma abordagem restaurativa na condução dos processos envolvendo atos infracionais e na execução das medidas socioeducativas Entretanto, é apenas em 2005 que os experimentos colhidos em Porto Alegre desenvolvem-se para dar início a um dos três projetos-piloto de Justiça Restaurativa brasileira. A efetivação destes esforços se deu, principalmente, por meio da Associação dos Juízes do Rio Grande do Sul (AJURIS), que já havia, em 2004, instituciona- lizado o núcleo de estudos em Justiça Restaurativa. Em linhas gerais, verifica-se que o projeto em questão tem como principal objetivo a utilização da Justiça Restaurativa para a solução de conflitos. De acordo com Lira (2009, p.396):

[...] o projeto em tela busca a prevenção e desjudicialização, mas principalmente a restauração do ofensor e a reparação dos danos causados à vítima e à comunidade para que se consiga a solução de problemas causados pelo crime. Assim, pode servir de veículo importante para aperfeiçoar as relações entre as pessoas e promover a responsabilidade, valorizando as necessidades de todos os envolvidos direta ou indiretamente (ofensor, vítima, familiares, comunidade), a fim de buscar respostas efetivas à solução de conflitos.

Vale ressaltar que o projeto em questão concentra-se em dirimir conflitos envolvendo infrações praticadas por crianças e adolescentes, não se falando em crime, mas sim em atos infracionais. Ainda assim, como afirma a autora no trecho supracitado, a busca pela responsabilização e reparação das consequências da ofensa, além do envolvimento ativo das partes conflitantes, das famílias e da própria comunidade, são pontos primordiais no projeto sob análise. Inicialmente, observa-se que o foco do projeto-piloto supracitado encontrava-se no tratamento diferenciado do próprio poder judiciário aos jovens praticantes de ato infracional. Procurava-se introduzir as práticas de 
justiça restaurativa no próprio processo de apuração do ato infracional, utilizando-se uma nova abordagem no que toca ao contato com o ofensor, bem como por meio da participação da vítima, quando possível. Da mesma forma, a aplicação das medidas socioeducativas não poderia focar na pura sanção do jovem infrator, mas sim, na reparação do dano causado. Sob esta ótica, pode-se afirmar que o projeto porto-alegrense coaduna com a visão maximalista da Justiça Restaurativa, por haver uma preocupação maior com os resultados e não por inteiro com o meio processual utilizado para atingi-los.

Todavia, salienta-se que o objetivo do projeto em questão é o de dar uma abordagem diferenciada aos procedimentos voltados às crianças e adolescentes infratores, por meio da capacitação dos atores envolvidos e na aplicação de medidas socioeducativas condizentes com o ideal restaurativo.

Ao institucionalizar as práticas restaurativas da $3^{\text {a }}$ Vara da Infância e Juventude da Comarca de Porto Alegre, o TJRS procurava expandir também a área de aplicação destas. Neste sentido, o intuito principal do projeto piloto era o de aplicar progressivamente a Justiça Restaurativa em quatro áreas distintas, englobando os processos judiciais, as medidas socioeducativas, os conflitos no ambiente escolar e também os ocorridos na comunidade. Com relação à aplicação da Justiça Restaurativa nos processos judiciais em andamento, tem-se utilizado duas formas para lidar com o conflito: a primeira, ocorrendo antes de o magistrado aceitar a representação e, assim, dar andamento ao processo judicial; a outra durante a execução da sentença. Na primeira hipótese, o magistrado propõe a realização de círculos restaurativos, buscando a aproximação das partes e a decisão quanto ao que deve ser feito para reparar o dano causado. $\mathrm{Na}$ segunda, o adolescente é acompanhado por uma equipe multidisciplinar, a qual avalia-o e determina sua aptidão para participar dos círculos restaurativos, procurando, por meio destes, encontrar uma solução mais adequada ao caso concreto. Observa-se que o projeto-piloto em questão visa a aplicação da Justiça Restaurativa durante o procedimento de apuração do ato infracional e também após a aplicação da medida socioeducativa. Logo, o fato de não ter sido possibilitado o procedimento restaurativo durante o curso do processo judicial não impede a busca por uma solução imbuída de caráter reparador. Desta forma, os jovens em cumprimento de medidas socioeducativas, em especial as privativas de liberdade, são submetidos a procedimentos de caráter restaurativo. Estes procedimentos envolvem a responsabilização e conscientização da infração cometida, mas também sua reintegração social, contando, inclusive, com o suporte socioeducativo e familiar, essenciais para a recuperação do indivíduo em formação. Entre os objetivos do projeto em tela, destaca-se a extensão das técnicas restaurativas, atingindo também os conflitos ocorridos nas escolas e nas comunidades carentes. Neste sentido, havendo conflitos entre adolescentes, o Poder Judiciário é acionado 
para oferecer a possibilidade de sanar o conflito por meio do procedimento restaurativo, o qual depende da aceitação dos envolvidos.

Destaca-se a utilização destes mecanismos em bairros carentes, sobretudo quanto à prática de atos infracionais de menor potencial ofensivo (Milazzo, 2008).

Considerando-se que antes mesmo de sua institucionalização, os resultados colhidos pela aplicação da Justiça Restaurativa em Porto Alegre já mostravam-se positivos, após 2005 estes melhoraram. Logo nos primeiros anos de funcionamento do projeto Justiça para o século $X X I$, mais de trezentos procedimentos restaurativos já haviam sido realizados, bem como mais de cinco mil pessoas haviam participado dos procedimentos de formação para aplicação da Justiça Restaurativa. Entre os anos de 2010 e 2012, o projeto-piloto em tela atendeu mais de 800 casos de conflitos envolvendo adolescentes em conflito com a lei. Segundo o relatório realizado pelo Central de Práticas Restaurativas do Juizado Regional da Infância e Juventude da Comarca de Porto Alegre, em 2012, entre os meses de janeiro e agosto foram recebidos 261 casos. Dentre estes, 98 casos haviam sido encerrados antes do início do procedimento restaurativo e 84 casos permaneciam em andamento; contudo, nos 79 casos levados até o final do procedimento restaurativo, todos haviam sido solucionados e os acordos firmados entre as partes foram cumpridos. Em que pese o percentual de casos em que não tornou-se possível a aplicação do método restaurativo, destaca-se os resultados relativos aos procedimentos leva- dos a cabo, nos quais houve $100 \%$ de cumprimento dos acordos firmados. Evidencia-se, por este dado, que a participação ativa das partes envolvidas no conflito tende a garantir medidas mais efetivas no que tange à reparação do dano - englobando tanto a responsabilização do infrator como a satisfação da vítima. Imperioso destacar que o projeto Justiça para o século XXI é tido como referência nacional no que toca à sua metodologia e formação de profissionais capacitados para as técnicas de justiça restaurativa. Observa-se, neste ponto, uma sutil diferença entre o projeto em questão e o projeto sul-caetanense anteriormente analisado. Enquanto o primeiro surgiu no âmago do Poder Judiciário e, posteriormente, voltou-se às escolas e à comunidade, o último foi concebido desde o início como uma parceria entre a Secretaria de Educação e o órgão judicante, com ênfase na atuação no ambiente escolar.

\section{A Experiência de Joinville e Santa Ca-} tarina

De acordo com Niekiforuk e Ávila, o projeto existente na Comarca de Joinville iniciou-se no ano de 2003, sendo implementado na Vara da Infância e da Juventude pelo juiz Alexandre Morais da Rosa. O magistrado em 1999 contou com a assessoria de Juan Carlos Vezulla e Luis Alberto Warat na criação de um projeto de mediação criminal aplicado a adolescentes, inspirado pela experiência de Barcelona. Com o título inicial de "Projeto Mediação", e posteriormente denominado Projeto Justiça Restaurativa, o intuito do projeto joinvillense era a aplicação da Justiça Restaurativa aos ca-

Pensamiento Americano Vol. 11 - No. 20 • Enero-Junio 2018 • Corporación Universitaria Americana • Barranquilla, Colombia • ISSN: 2027 -2448 • PP. 141-155 http://coruniamericana.edu.co/publicaciones/ojs/index.php/pensamientoamericano 
sos envolvendo adolescentes em conflito com a lei na Comarca. Para tal, visou-se a utilização da técnica de mediação entre vítima e ofensor, semelhante ao método utilizado em Porto Alegre, e que viria a oficializar-se como uma das pelo projeto Justiça para o século XXI. Para dar instrumentalidade ao projeto em questão, foi necessário montar uma equipe com profissionais de diversas áreas, em especial, psicólogos e assistentes sociais, além dos próprios servidores do Poder Judiciário. A respeito do assunto, Niekiforuk e Ávila (2008, p.58) afirmam que:

[...] por meio da portaria $05 / 2003$, no âmbito da Comarca de Joinville, tendo em vista a previsão legal dos serviços auxiliares contida nos artigos 150 e 151 do Estatuto da Criança e do Adolescente (ECA), instituiu-se a equipe interprofissional, formada por profissionais qualificados na área de serviço social, orientação educacional, direito e psicologia, dentre outros, considerando-se como seus agentes as Assistentes Sociais Forenses, os Comissários da Infância e da Juventude, Educadores Educacionais, Psicólogos e demais profissionais atuantes na Unidade, indicados pelo Juiz de Direito, especificamente para atuar nos casos de apuração de atos infracionais, bem como a aplicação de técnicas de mediação em questões que envolvam adolescentes autores de ato infracional, fomentando uma abordagem restaurativa entre adolescentes, seus responsáveis, vítimas e comunidade.
Verifica-se que a estrutura montada pelo Projeto Justiça Restaurativa de Joinville volta-se para dar a o amparo necessário ao adolescente infrator, seus familiares e a vítima. Procura-se, por meio da presença de profissionais da psicologia, educação e assistência social, garantir o acompanhamento adequado ao procedimento de mediação, tendo em vista a complexidade deste ato sob o ponto de vista subjetivo. Abrir se publicamente e reviver a situação em que se deu a infração é um processo árduo tanto para o infrator como para a vítima, e, para que seja bem sucedido, requer apoio de indivíduos devidamente capacitados. Quanto aos conflitos passíveis de aplicação da justiça restaurativa, observa-se que a apuração dos atos infracionais é o foco do projeto sob análise. Da mesma forma, outros eventos envolvendo adolescentes autores de ato infracional podem ser analisados sob a ótica restaurativa, principalmente no que toca a conflitos familiares ou comunitários envolvendo o jovem em questão. O encaminhamento do adolescente ao procedimento restaurativo pode se dar no momento da representação ou durante o processo de apuração do ato infracional. Em ambos os casos, o magistrado, verificando a possibilidade de aplicação do mesmo, solicitará o parecer da Equipe Interprofissional, a qual é responsável pela condução da mediação entre vítima e ofensor. Além da ausência de violência ou grave ameaça nos atos infracionais, o projeto joinvillense dá preferência aos adolescentes primários e autores de atos infracionais de menor gravidade.

A mediação promovida pela Equipe Inter- 
profissional tem com primazia a reparação das conseqüências da infração, e não na reprodução do ato infracional em si. Por este motivo, o foco do procedimento é em fazer com que as partes convirjam a respeito da solução adequada ao caso, sem aterem-se à discussão da gravidade ou reprovabilidade da conduta praticada, o que implicaria na utilização da lógica iminente na Justiça Retributiva. Morais Da Rosa (2008, p.209) afirma, ao tratar do projeto em questão, afirma que:

No projeto que se leva a cabo no Juizado da Infância e Juventude de Joinville - SC, por exemplo, a perspectiva é a de buscar com o sujeito a emancipação, como bem demonstrou Juan Carlos Vezzulla. Assim é que, dentro da atuação da instituição, abre-se uma possibilidade de diálogo com o adolescente, seus familiares, seu grupo e a vítima, via círculo restaurativo. Com isto o adolescente pode discutir o acontecido, ter responsabilização e perceber as conseqüências de sua conduta.

Segundo o magistrado, o procedimento tem apresentado resultados positivos, principalmente no que toca à conscientização do adolescente quanto às conseqüências de sua conduta. Este fator é essencial para que haja a efetiva reparação dos danos causados, fazendo com que a situação ofensiva seja de fato enfrentada e superada. Deve ater-se, no entanto, à tendência de monetização da reparação, buscando-se atos que promovam a reintegração do infrator à comunidade que o cerca. Tal cuidado é necessário tendo em vista que a compensação pecuniária é, na maioria das vezes, um meio de recalcar o conflito, sem, necessariamente, superá-lo. De acordo com Niekiforuk e Ávila (2008, p.59), o procedimento adotado pelo projeto Justiça Restaurativa, de Joinville, se dá da seguinte forma:

[...] o procedimento restaurativo se dá a partir da derivação (remessa dos autos em que a infração é apurada) para a equipe técnica, com a concordância do adolescente, seus responsáveis e advogado. Após este momento, é realizada uma pré-mediação, entrevista prévia feita por um mediador com o adolescente, seus pais ou representante e seu advogado para explicar os fundamentos da proposta (voluntariedade, sigilo, respeito, etc.). Caso aceita a participação, com os facilitadores, busca-se a concórdia, à qual, num segundo momento, pode impactar a vítima. Tudo isso, mediante uma abordagem que respeita o adolescente, sua singularidade e não quer fazer ortopedia moral.

Os autores ainda afirmam que o magistrado e o representante do Ministério Público não participam da mediação restaurativa, restringindo-se à apresentação de conclusões após o término do processo. Atentam, ainda, para o papel importante do mediador na promoção do contato entre a vítima e o ofensor, bem como o benefício concedido pelo procedimen- 
to às partes, que possam compreender e resolver seus problemas, descobrindo uma solução mais humana para o conflito, sem imposições, mas responsabilizações. Percebe-se que o procedimento utilizado pela Vara da Infância e da Juventude da Comarca de Joinville promove a Justiça Restaurativa por meio da mediação entre vítima e ofensor. Salienta-se a importância da Equipe Interprofissional no andamento deste projeto, no sentido de assessorar as partes e garantir ao adolescente infrator o tratamento condizente com seus direitos fundamentais, tendo como foco sua recuperação; além, é claro, da reparação do dano causado. É válido destacar, ainda, que um projeto independente, mas de grande valia no tocante à aplicação da Justiça Restaurativa em Joinville, foi criado no ano de 2014. Trata-se do Núcleo de Mediação de Conflitos da Polícia Militar de Santa Catarina, programa voltado para a mediação de adultos nos casos de conflito entre pessoas do mesmo círculo de convivência. $\mathrm{O}$ atendimento, realizado em parceria com a Universidade UniSosiesc destina-se à população carente e visa a aplicação da mediação nos casos envolvendo familiares, vizinhos, e amigos, procurando aparar as arestas entre as partes de modo consensual.

Pelo exposto, verifica-se que a aplicação da Justiça Restaurativa em Joinville remete ao ano de 2003, sendo utilizada a mediação entre vítima e ofensor em sede de apuração de atos infracionais. Tendo o projeto Justiça Restaurativa sido iniciado na Vara da Infância e Juventude, por conseqüência sua aplicação destina-se aos adolescentes em conflito com a lei. Verifica-se que a utilização da mediação pela Vara da Infância e da Juventude torna a prática joinvillense semelhante àquela utilizada no projeto piloto Justiça para o século XXI. Em ambos os casos, parte-se da aplicação da Justiça Restaurativa dentro do processo, imperando uma visão centrada nas finalidades. Logicamente, pelo exposto, observa-se que o procedimento de mediação é pautado nos princípios da Justiça Restaurativa em garantir um método diferenciado de tratamento dos conflitos envolvendo jovens, visando sua conscientização, bem como a satisfação dos interesses do ofendido.

\section{Considerações Finais}

Verifica-se que os resultados positivos obtidos pelos projetos piloto de Justiça Restaurativa levaram à propagação de projetos em diversas localidades brasileiras, na aproximação entre as partes e na reparação do dano. Tal prática tem sido utilizada, sobretudo, em relação às crianças e adolescentes e no ambiente escolar, objetivando o efetivo amparo dos jovens que, pelos mais diversos motivos, são levados à prática do ato infracional. Pelos dados analisados até o momento, percebe-se que as regiões Sul e Sudeste do Brasil destacam-se pela adoção de práticas de Justiça Restaurativa há mais tempo, possuindo, inclusive, dois dos projetos-piloto criados em 2005. No entanto, a região Nordeste apresenta programas com resultados significativos na aplicação da Justiça Restaurativa.

Até o presente momento, foram analisados diversos projetos de aplicação da justiça res- 
taurativa em território brasileiro. Trata-se de programas existentes em diversos estados brasileiros que buscam a aplicação de métodos de Justiça Restaurativa como forma alternativa de tratamento dos conflitos penais ou infracionais, nos casos envolvendo crianças e adolescentes. Verificou-se que as práticas de Justiça Restaurativa no Brasil tiveram seu ponto de partida no final do XX, acompanhando o movimento em prol de métodos alternativos de solução de conflitos, que tinha como marco nacional a Lei $\mathrm{n}^{\mathrm{a}}$ 9.099/95, que instituía os Juizados Especiais.

Contudo, a Justiça Restaurativa aplicada à época no país embasava-se puramente nos modelos internacionais, sem um modelo nacional oficial. Foi apenas em 2005 que a Justiça Restaurativa tornou-se uma prática oficial no Brasil, por meio da criação dos três projetos-piloto analisados anteriormente. Tais projetos, instalados nas cidades de São Caetano do Sul, Porto Alegre e no Distrito Federal, criados através da atuação conjunta do Ministério da Justiça, do PNUD e Poder Judiciário local, tornaram-se referência para a aplicação da Justiça Restaurativa brasileira, influenciando o surgimento de tantos outros projetos ao longo do território nacional. Salienta-se que os projetos-piloto brasileiros de Justiça Restaurativa forma criados em comarcas que já possuíam algum contato com práticas embasadas no ideal restaurativo. Além disso, os três projetos desenvolveram-se com diferentes enfoques, abordando vários eixos de aplicação que decorrem da Justiça Restaurativa: o projeto de São Caetano voltou-se aos conflitos envolven- do crianças e adolescentes no âmbito escolar, o de Porto Alegre, aos adolescentes em processo de apuração de ato infracional e medidas socioeducativas; e o projeto do Distrito Federal, aos crimes de menor potencial ofensivo, sobretudo conflitos de vizinhança e familiares. A propagação da Justiça Restaurativa a partir da oficialização dos projetos-piloto no ano de 2005 é perceptível nos demais projetos analisados. Ainda que alguns deles tenham iniciado na mesma época dos projetos oficiais, ou, como no caso do projeto joinvillense, poucos anos antes, o modus operandi bebe da fonte dos três projetos, adequando-se à proposta local. Há, portanto, um intercâmbio de experiências de Justiça Restaurativa no Brasil. A adoção de práticas de Justiça Restaurativa tem sido cada vez mais fomentada pelo Conselho Nacional de Justiça, seja pela formação de mediadores e conciliadores, ou por meio de campanhas de incentivo $^{1}$. De modo geral, após uma década de utilização da Justiça Restaurativa no Brasil, verifica-se que muitos avanços foram obtidos, e, simultaneamente, há ainda um longo caminho para que esta forma de justiça esteja sedimentada em território brasileiro. Contudo, em especial no que toca às crianças e adolescentes, e aos conflitos no ambiente escolar, a metodo-

1. Verifica-se que, recentemente, em 12 de maio de 2015, o CNJ e a Associação Brasileira de Magistrados lançaram a campanha nacional Justiça Restaurativa no Brasil, voltada para a divulgação da Justiça Restaurativa e a mobilização institucional interna e externa para a criação de novos programas para aplicar as práticas de Justiça Restaurativa. Conselho Nacional de Justiça. CNJ e AMB lançam campanha nacional para ampliar Justiça Restaurativa. In: Site Conselho Nacional de Justiça. Disponível em: <http://www.cnj.jus.br/ noticias/cnj/79333-cnj-e-amb-lancam-campanha-nacional-para-ampliar-justica-restaurativa>. Acesso em: 15 maio 2015. 
logia e os ideais restaurativos demonstram ser o modo mais adequado para lidar com os conflitos.

\section{Referências bibliográficas}

Lira, A. Reseña de "Justiça para o século 21: instituindo práticas restaurativas: semeando justiça e pacificando violências". In L. Bracher \& S. Silva (2009), Revista Diálogo Educacional, 9(27), 395-399. Disponível em: <http://www.redalyc.org/ pdf/1891/189117298012.pdf>. Acesso em: 12 abr. 2015.

Melo, E. R., Ednir, M. \& Yazbek, V. C. (2008). Justiça restaurativa e comunitária em São Caetano do Sul: aprendendo com os conflitos a respeitar direitos e promover cidadania. São Paulo: CECIP.

Melo, E. R. (2006). Justiça e educação: parceria para a cidadania: Um projeto de Justiça Restaurativa da Vara da Infância e da Juventude da Comarca de São Caetano do Sul envolvendo a rede escolar da comarca. Disponível em: http://www. mpdft.mp.br/portal/pdf/unidades/ promotorias/pdij/XXICongressoNacional_ABMP/1\%20Experiencia $\% 20$ \%20Eduardo\%20Rezende $\% 20$ Melo\%20 08.05\%20-\%20G7.pdf. Acesso em: 12 abr. 2015.
Milazzo, C. M. C. (2008). Justiça Restaurativa: caminhos de fraternidade, direitos humanos e dignidade social. Dissertação (Direito). Pontifícia Universidade Católica de Goiás, Goiânia.

Niekiforuk, M.; Ávila, G. N. de. 2008. Justiça Restaurativa em Santa Catarina: a experiência joinvillense na implementação do projeto de Justiça Restaurativa junto à Vara da Infância e Juventude. Revista Unisul de Fato e de Direito, Joinville, [s.v.], 55-67. Disponível em: <http:// www.portaldeperiodicos.unisul.br/index.php/U_Fato_Direito/article/viewFile/1034/864>. Acesso em: 09 abr. 2015. Polícia Militar do Estado de Santa Catarina (2014). Disponível em: <http://www. $\mathrm{pm} . \mathrm{sc}$.gov.br/noticias/joinville-ganha-o-1-centro-judiciario-de-solucao-de-conflitos-e-cidadania-e-o-1-nucleo-de-mediacao-de-conflitos-da-policia-militar-de-santa-catarina.html>. Acesso em: 04 maio 2015.

Morais Da Rosa, A. (2008). Justiça Restaurativa e Ato Infracional: práticas e possibilidades. Revista IOB de Direito Penal e Processual Penal, 9(50), 205-213. 